\title{
CHICANOS, BORICUAS Y CUBANOS: LAS FICCIONES COLECTIVAS
}

\author{
Dra. Patricia Casasa García*
}

La verdadera significación histórica de escribir consiste en que ha incrementado nuestra capacidad para crear ilusiones totalizadoras con las cuales tenemos poder sobre las cosas o sobre los otros como si fueran cosas. Toda la ideología de la significación representacional es una ideología del poder. ${ }^{1}$

RESUMEN: Hoy en día las principales actitudes literarias chicanas, puertorriqueñas y cubano-americanas, tanto de hombres como de mujeres, se reúnen en torno a la búsqueda de autodeterminación, la autodefinición, junto con un proceso de autoinvención entre varias culturas. Estas actitudes toman una perspectiva crítica, consciente de los rastros históricos que aporta, y cuya visión tiene como resultado un discurso teórico del proceso histórico con respecto al individuo y a la familia en sus momentos íntimos y en sus procesos cognitivos.

PALABRAS CLAVE: Autodefinición, Ficción colectiva, Literatura chicana/latina, Autoinvención.

ABSTRACT: Nowadays the main Chicano, Puerto Rican and Cuban American literary features, of men and women, are in search of selfdetermination and self-definition, along with a process of self-invention among several cultures. These features have a critical perspective that takes into consideration the historical traces, and the resulting vision is a theoretical discourse of the historical process regarding the person and the family in its more intimate moments and cognitive processes.

KEYS WORDS: Self-definition, Collective fiction, Chicano/Latino literature, Self-invention.

* Escuela Nacional de Enfermería y Obstetricia - UNAM (pcasasa@eneo.unam.mx).

1 Tyler, S.A., "Etnografía posmoderna: desde el documento de lo oculto a lo oculto del documento", en J. Clifford y G. Marcus [comps], Writing Cultures, Berkeley, University of California Press, pp. 122-140 (trad. en español en este volumen y en Retóricas de la Antropología, 1991). 
Como en toda minoría, existe gran diversidad entre las poblaciones chicana, puertorriqueña y cubana en Estados Unidos con respecto a su identidad étnica, que se detecta desde aquellos que se consideran mexicanos, méxico-americanos, norteamericanos de ascendencia mexicana, como otros que se auto identifican a su vez como latinos o hispanos, de origen español, cubanos, cubano-americanos, puertorriqueños, nuyorricans, o hasta los que se sienten anglosajones. Algunos son bilingües y otros monolingües, tanto en inglés como en español. Existen diferencias también entre aquellos que han tenido acceso a la educación y los que no lo han logrado, la gama oscila entre los que son más americanizados hasta aquellos que están tratando de encontrar sus raíces, variando también, en aquellos que aceptan o rechazan sus roles tradicionales de mujer o de varón heterosexual.

La mayoría de las obras chicano/latinas están escritas en inglés, con frases ocasionales en español, cuyo impacto afectivo a menudo requiere de una interpretación más allá de lo literal. La selección de dichas frases es muy especial, con referencia al sistema de símbolos y significantes de la cultura mexicana y latinoamericana. Así, en este contexto lingüístico se pone en juego las categorías cognitivas de varias culturas, la norteamericana, la cubana, la puertorriqueña o la mexicana, planteando una yuxtaposición cultural para forjar la autodefinición y la autoinvención, además de la apropiación del inglés como instrumento propio de comunicación. Este proceso encuentra analogías con el proceso histórico de apropiación del castellano en México y en toda Latinoamérica.

Hay muchas etiquetas para referirse a la literatura chicana/latina en general. Se le define como literatura de protesta social, de actuación (performance), del proletariado, de estética mainstream o sea del medio anglo dominante, feminista, y también puede caer en la categoría de gay. Sin embargo, la suma de estas etiquetas hace que la literatura chicana/latina tenga un panorama amplio y enriquecedor.

En los últimos años la producción femenina ha venido a incrementar el acervo literario chicano/latino. Existe una nueva generación de escritoras chicanas, puertorriqueñas y cubano-americanas, que surge a 
la sombra de movimientos sociopolíticos, como el chicano y el latinoamericano, así como del movimiento feminista norteamericano. Los primeros, caracterizados por una voz cultural sumamente masculina y el segundo, por la voz de la mujer blanca de clase media norteamericana. No obstante, en la década de los ochenta, las escritoras chicano /latinas, apoyadas por lo que fue el reto político y literario al publicarse This Bridge Called My Back (1981), editado por Cherrie Moraga y Gloria Anzaldúa, clasificado como uno de los diez mejores libros en Estados Unidos, expresaron por primera vez su determinación a ser reconocidas como diferentes. Esta obra recoge la protesta contra el racismo feminista norteamericano y contra el sexismo, ya que en general tales actitudes marginan a la mujer de color, aun cuando también se veía la necesidad de emancipación. El libro reúne una serie de testimonios que expresan la experiencia de mujeres socialmente marginadas como las chicanas, cubanas, puertorriqueñas, negras, orientales e indígenas. Se insiste en el análisis de la situación sociohistórica, la producción crítica, teórica y literaria de todas ellas, pero únicamente a través de la perspectiva de los tres órdenes sociales y categorías analíticas que siempre han regido sobre su existencia, esto es género / sexo, raza / cultura y estatus socioeconómico, recogiendo los estudios sobre las mujeres latinas, chicanas y de color en el ámbito universitario norteamericano. ${ }^{2}$

Ana Castillo, por ejemplo, tiene por norma no asistir a los talleres de literatura manejados por norteamericanos, pues teme perder su "voz" debido a la presión para usar el inglés en tales talleres. Sin embargo escribe en inglés, y a veces en español, pero elude la influencia dominante. Castillo proviene del proletariado e insiste en su posición social como punto de referencia. Para ella, como para muchos otros escritores y escritoras que se niegan a asistir a tales talleres, es una cuestión de autoprotección para cultivar dicha "voz" y la temática propia. Para otros como Sandra Cisneros, Bárbara Brinson Curiel o Alberto Ríos, la

2 Ibid., p. 208. 
asistencia a dichos talleres les ha servido para apropiarse de la técnica narrativa o poética y aplicarla a sus propios intereses. ${ }^{3}$

Sandra Cisneros, quién también surge de la clase baja, cuenta que en Iowa no podía escribir porque se encontraba fuera de su ambiente, junto a norteamericanos de clase media alta que describían jardines esculpidos con exquisita finura, casas hermosas, y que ella solamente tenía para describir las grotescas imágenes del barrio, las cuales no podía traducir a bellas imágenes como sus compañeros, por la vergüenza que le producía pertenecer a una clase socialmente inferior y fuera de los cánones norteamericanos de clase media. Hasta su segundo año en la universidad rompió su silencio literario y se propuso escribir sobre el barrio, el gueto, la basura, las cucarachas y las ratas, lo cual era exponer su privacidad y su experiencia. Sin embargo al describirlo ha logrado imágenes reales, que ponen al descubierto la realidad de la vida cotidiana de los habitantes de dichos lugares y de las penurias de los grupos considerados minorías.

Las mujeres han confrontado muchos problemas dentro de la lucha por los derechos humanos, pero son escasamente reconocidas, como dice Martha Cotera, una activista chicana, "cuando la mujer habla, la comunidad oye, pero ella raramente lo hace."4

El Movimiento Chicano centró su crónica en hechos actuados por los hombres que en gran parte han ignorado los problemas de las mujeres, lo que refleja la triple opresión a la que se encuentran sujetas dentro de una sociedad anglosajona, y dentro de su propio grupo: la sexual, la étnica y la socioeconómica.

La mayoría de los analistas coinciden en señalar que al irse conformando y delineando el movimiento con base en sus reivindicaciones de grupo y otras demandas, se hace claro que éstas se retroalimentan

3 Norma Alarcón, "La literatura de la chicana; un reto sexual y racial del proletariado," en Aralia López et al., Mujer y literatura mexicana y chicana: culturas en contacto, México, COL-Frontera Norte, 1990, pp. 208-209.

4 Martha P. Cotera, The Chicana Feminist, Information Systems Development, Austin Texas, 1974. 
hacia el interior, y así como el varón chicano es marginado por la sociedad blanca dominante, a su vez él rechaza al sector femenino de su propia comunidad, ${ }^{5}$ de esta manera sus demandas, necesidades, problemas, etc., quedan fuera de toda consideración.

Ana Castillo dice que el movimiento chicano /latino de finales de los años sesenta y principios de los setenta sirvió de catalizador para la perspectiva sociopolítica xicanista, término usado por las feministas, y añade que ella ha realizado además un análisis de cómo ha influido el catolicismo para delinear la identidad de las mujeres como activistas políticas dentro de una sociedad eminentemente machista.

El movimiento fue influenciado en gran parte, por una ideología marxista, enfocada al aspecto económico de las clases proletarias chicanas. Cuando se hizo la conexión entre la religión institucionalizada y la dependencia de las clases oprimidas, se comenzó a rechazar a la Iglesia, al menos en el principio, y el movimiento confundió, en ese momento, espiritualidad con Iglesia; en la práctica, la mayoría de los activistas no comulgaban con el catolicismo. Esta toma de conciencia en México así como entre los latinos en Estados Unidos significa, frecuentemente, un movimiento hacia el socialismo. ${ }^{6}$

Los chicanos, de hecho, son el producto de dos conquistas; la primera realizada por los españoles sobre los indios, que dio como resultado una cultura mestiza, elaborada con base en elementos indígenas e hispanos. La segunda, una conquista anglosajona sobre la mexicana que ha dado como producto la chicana que permanece hasta la fecha formalmente establecida dentro del territorio estadounidense. En ambos casos, la opresión se ha presentado por doble vía; esto es, por canales étnicos y económicos, creando como consecuencia un racismo institucionalizado que se ha vuelto la norma cotidiana.

5 Alfredo Mirandé y Evangelina Enríquez, La chicana, The University of Chicago Press, Phoenix Edition, 1981.

6 Ana Castillo, Massacre of the Dreamers, Plume/Penguin, Women studies /Latino Literature, 1995, pp. 12-13. 
El colonialismo interno se centra más que nada en la idea de un grupo étnico-cultural, subsistiendo en una situación de explotación que al no poseer un control sobre sus instituciones sociales básicas, como la educación, la política, la religión, y otras que son controladas por un sistema ajeno, propician el desarrollo de mecanismos informales que van destruyendo la forma de vida característica de este grupo, que solamente se ha podido mantener y perpetuar a través de la familia, que funciona como mecanismo de defensa para resistir los embates de la cultura dominante.

Con ello parece ser que la identidad chicano /latina en Estados Unidos se está transformando continuamente, a través de la actuación e interpretación de papeles culturales que aparecen en los textos literarios y en otros espacios de producción artística; estas actuaciones (performances) generan, a su vez, representaciones literarias diversas con respecto a la etnicidad. Las narrativas asimilacionistas de los inmigrantes, las novelas de sexualidades marginadas y las historias de realismo mágico, participan en la desestabilización de las diferentes categorías de identidad contenidas en la etiqueta de "chicano /latino-estadounidense".

En muchos de los trabajos literarios chicano /latinos, las actuaciones que parecen afirmar las normas y tradiciones de los caracteres culturales ancestrales funcionan, incluso, como subversivas frente a la noción esencial de identidad étnica. Por ello si se enfoca el proceso hacia la identificación de cómo funcionan los signos de exceso al hacer actuaciones que constituyen la identidad, y se propone que lo que se ha visto como esencia cultural chicana, puertorriqueña, cubana, etc., que consideran los críticos que está emanada de la comunidad y por lo tanto la traducen como estándares de autenticidad, se llega a la conclusión de que esta "esencia" no es más que la "invención de una ficción colectiva". 8

$\begin{array}{ll}7 & \text { Loc. cit. } \\ 8 & \text { Loc. cit. }\end{array}$ 
Es importante hacer notar que los trabajos de las escritoras inmigrantes latinas, como la puertorriqueña Judith Ortiz Cofer: The line of the Sun (1989), Silent Dancing: A Partial Remembrance of a Puerto Rican Childhood (1990) y The Latin Deli (1993) y la dominicana Julia Álvarez: How the Garcia Girls Lost their Accents (1991), son ejemplo de lo anteriormente descrito, ya que en dichas obras se habla de la asimilación y de la adopción de valores culturales dominantes por parte de los hijos de los inmigrantes, y de cómo las actuaciones de identidad están influenciadas por la importancia relativa que reviste para todos ellos el ser aceptados como estadounidenses.

De acuerdo con algunos analistas, dichas novelas revelan que la identidad - ya sea puertorriqueña, dominicana, cubana, mexicana, ecuatoriana, etc., así como la anglosajona-, son susceptibles de ser actuadas (performative), y por lo mismo no son estables o fijas. Las normas dominantes mencionadas en los textos son los estándares con los cuales son medidos los "excesos" étnicos. La asimilación total de los individuos es impedida por la recurrencia de conductas culturales peculiares no aceptables para la cultura huésped, como por ejemplo la manera de vestir demasiado exagerada, llena de color e inapropiada; la manera de hablar a grandes voces, de ser ruidosos, o la preferencia por la música estridente tipo "salsa" o la falta de habilidad para hablar inglés estándar sin acento, además de los inevitables rasgos físicos no "blancos" o la persistencia de una identidad cultural idealizada y una percepción casi mítica del lugar de origen. ${ }^{9}$

Las novelas están escritas por hijas de inmigrantes, y expresan una dinámica generacional muy importante para su análisis, ya que a través de los personajes se hace una crítica a la presión que ejercieron los padres de las autoras para hacer de las hijas unas completas angloamericanas, cuando quisieron que se asimilaran sin cuestionamientos a la cultura norteamericana, sin embargo ellas se auto perciben más que nada, como negociadoras entre las dos lenguas y culturas.

9 Ibid., p. 32. 
We shopped in stores our neighbors never couldn't afford or feared to enter, and my mother had a charge account at Penney's. The only thing he couldn't get her to do was move out of the crowded barrio of El Building. But within the four walls of our flat he did everything possible to separate us from the rabble. By dressing better and having more than any of the children en El building, we were kept out of their ranks; by having less than our classmates at Saint Jerome's, we never quite fitted en that society either. ${ }^{10}$

A pesar del esfuerzo de los padres para eliminar todo contenido étnico en la conducta de las hijas, por ejemplo inscribiéndolas en escuelas privadas de prestigio como sucede en la novela de Julia Álvarez, How the Garcia Girls Lost Their Accents (1991), de todas formas sus "excesos" en las actuaciones las delatan como extranjeras. La experiencia que las autoras viven con el proceso de asimilación y aculturación y las cuestiones culturales, las lleva a explorar la identidad a través de la literatura. Su clara percepción del problema, las mueve a reconocer el papel que están desempeñando como productoras en el proceso de inventar las tradiciones culturales y la identidad étnica por medio de la escritura. ${ }^{11}$

En otro plano, la intersección y el conflicto entre la etnicidad y la sexualidad se ve claramente delineado en las novelas de los escritores chicanos como John Rechy en City of_Night (1963) y Sheila Ortiz Taylor en Faultline (1982) y Southbound (1990); en ellas los caracteres de

10 Judith Ortiz Coffer, The Line of the Sun, Athens, University of Georgia Press, 1989, p. 178. "Nosotros comprábamos en tiendas en las que nuestros vecinos no podían comprar, e incluso temían entrar y mi madre tenía una cuenta en Penney’s. La única cosa que él no pudo darle fue cambiarse fuera del atestado barrio de El Building. Pero dentro de esas cuatro paredes del departamento, él hizo todo lo posible por separarnos de la chusma. Por vestir mejor y tener más que cualquiera de los chicos, en El Building nos mantuvieron fuera de la gente común; por tener menos que nuestros compañeros de clase en Saint Jerome's, nunca pudimos encajar en esa sociedad tampoco."

11 Julia Álvarez, How the Garcia Girls Lost Their Accents, Chapel Hill, Algonquin Books of Chapel Hill, 1991. 
homosexualidad y lesbianismo transgreden las normas sociales de ambas sociedades. La familia chicana solamente puede presentar un frente unido en contra de la dominación anglosajona, si sus papeles tradicionales masculino y femenino, mujer y hombre, son mantenidos. Según Cherry Moraga $^{12}$ la comunidad chicana considera que entre más estrictamente protejan sus roles sexuales dentro de la familia, ésta será más fuerte para resistir la amenaza de la cultura norteamericana, a la que consideran corrupta y degenerada y así, tanto las lesbianas como los gays pueden ser percibidos como no participantes en la resistencia centrada en la familia. ${ }^{13}$ Por eso, es necesario hacer notar que la represión de la sexualidad lesbiana y homosexual no es exclusiva de la sociedad chicana/latina. El lesbianismo y la homosexualidad son vistos como excesos en toda sociedad patriarcal, porque representan una amenaza para el orden social heterosexual del dominio masculino. Dichas actuaciones son percibidas, tanto por las comunidades machistas chicanas, puertorriqueñas, cubanas y angloamericanas, como amenazas para la unidad cultural ya que van en contra de la estructura familiar claramente definida, los valores y los roles de género tradicionales. ${ }^{14}$ Estas novelas al enfatizar las características lesbianas y homosexuales "deconstruyen” la noción primordial de género y de esencia cultural. ${ }^{15}$

Ambas novelas indican que las condiciones de lesbianismo y homosexualismo están constituidas a través de "actuaciones" que reflejan personajes con una identidad cambiante en una gran variedad de escenarios sociales. Los caracteres negocian continuamente entre las posiciones de los sujetos, amenazando la exclusividad de oposiciones tales como masculino/femenino, exilio/étnico, homosexual/heterosexual.

12 Cherry Moraga, Loving in the War Years: Lo que nunca pasó por sus labios, Boston, South End Press, 1983.

13 Karen Christian, Performance and the Construction of Identity in US Latino Fiction, Dissertation for the Degree of Doctor pf Philosophy in Spanish, University of California, Irvine, Manuscript, 1994.

14 Loc. cit.

15 Loc. cit. 
Por otra parte, la narrativa cubano-americana de Oscar Hijuelos en The Mambo Kings Play Songs of Love (1989) y de Elías Miguel Muñoz en The Greatest Performance (1991), sugieren que las actuaciones prescritas de "exceso" en el género (hiper masculinidad e hiper feminidad) son intrínsecas para la cultura cubana. En la obra de Muñoz, la autenticidad cubana está plasmada estrictamente a través de los roles de género. Los protagonistas de la novela que son homosexuales y lesbianas amenazan los paradigmas de identidad cultural de la comunidad de emigrantes al intercambiar estas construcciones de masculinidad y feminidad. En la novela de Hijuelos los protagonistas, al actuar de manera obsesiva el papel de latin lover, señalan lo inaccesible de la esencia masculina cubana. ${ }^{16}$ Al final de la novela de Muñoz, la trama incorpora su herencia cultural cubana dentro de una fantasía subversiva. Con esta herencia y con la infinita actuación falocéntrica de los protagonistas de Mambo Kings..., ambos autores sostienen la imagen de una cubanidad aparentemente auténtica, como un dibujo que parodia la noción de la esencia de la identidad. ${ }^{17}$

El "realismo mágico", al igual que el género y la actuación cultural, ha sido catalogado como un emblema de la esencia chicana/latina en Estados Unidos. Gracias a la amplia popularidad de lo que se denomina Latin American Boom Fiction, el realismo mágico se ha constituido para la sociedad anglosajona, como el modelo que define la esencia de la espiritualidad latina; de hecho las instancias místicas, milagrosas y mágicas que ocurren en los textos sirven para reforzar la conexión entre las literaturas latinoamericana y chicana /latina. ${ }^{18}$

Las obras de Cecile Pineda The Love Queen of the Amazon (1992), la de Ana Castillo So Far from God (1993), y la de John Rechy The miraculous Day of Amalia Gómez (1991), son consideradas parte de este tipo de literatura, y se prestan para analizar el proceso de inven-

\footnotetext{
${ }^{16}$ Christian, op. cit., pp. 32-33.

17 Loc. cit.

18 Ibid., p. 247.
} 
ción de la identidad chicana/latina, $\mathrm{y}$, al mismo tiempo, a través de ellas se puede explorar la reciente proliferación en Estados Unidos de la literatura de los chicanos, puertorriqueños y cubanos.

Sin embargo, el análisis de estas novelas tiene implicaciones que van más allá de simples imitaciones de un código estético. De diferentes maneras, las novelas cuestionan la noción de "esencia cultural" al problematizar, transformar y traslapar los signos tradicionales de la identidad chicana /latina. En el libro de Love Queen of the Amazon los sueños del personaje narrador Federico, expresan el deseo de capturar en su novela toda la historia latinoamericana y que ésta tenga la capacidad de envolver toda su esencia cultural, como por ejemplo cuando Ana Magdalena aparece casi desnuda contando la historia de que fue raptada, Federico, que estaba junto a ella cercano a un colapso de emoción, le dice en voz muy dulce, que será la heroína de la novela que él va a escribir:

I'll tell you what I'm going to do: I'm going to lock my self upstairs. And night and day, day and night, I'm going to write. I'm going to write something extraordinary. I can't be disturbed on any account. You are going to see to everithing: bills, the running of the house: I want three meals a day and a change of clothes. I'm going to give the world a major work, a stunning romance; it will spill over both the southern and northern hemispheres! I'm going to call it The Love Queen of the Amazon. And you, my darling, will provide just the right touch of inspiration. ${ }^{19}$

Pero irónicamente, al hacer el tratamiento no realista en la representación de eventos narrativos, la proliferación de incidentes mágicos, y por la concepción no lineal del tiempo, la novela sólo remarca la elusividad

${ }^{19}$ Cecile Pineda, The Love Queen of the Amazon, Boston, Little Brown and Co., 1992, p. 115. "Te diré que voy a hacer: Me encerraré arriba. Y día y noche, noche y día, voy a escribir algo extraordinario. No deberé ser interrumpido por ningún motivo. Tú te vas a encargar de ver todo: cuentas, el trabajo de la casa: Quiero tres comidas al día y un cambio de ropa. Le voy a dar al mundo el mejor trabajo, un romance asombroso; Lo voy a revelar en los dos hemisferios, norte y sur. Lo voy a llamar The Love Queen of the Amazon. Y tú, mi amor, vas a darle justo el toque de inspiración". 
de la realidad que intenta capturar, y al final el texto se le escapa de control, y únicamente puede presentar una visión fragmentada de su gran proyecto.

Como un ardid literario el realismo mágico le concede al personaje principal, Federico, una alternativa para no hacer una narración realista tradicional. Al hacer el tratamiento entre el realismo mágico y otros códigos del boom, Pineda establece una relación dialógica entre la ficción latinoamericana y la chicana/latina de Estados Unidos. ${ }^{20}$ La novela afirma la conexión que frecuentemente se hace entre las dos literaturas, pero únicamente con la perspectiva de que la literatura chicana/latina de Estados Unidos es escritura étnica americana con esencia latinoamericana.

Por otro lado, las novelas de Ana Castillo So Far from God (1993) y las de John Rechy The Miraculous Day of Amalia Gómez (1991), explícitamente expresan preocupaciones sobre la esencia y la problemática étnica, como se describe a continuación:

She disliked downward-slanting eyelashes -but not, as some people of her mother generation disdained them because they were supposed to signal a predominance of "indian blood". Unlike her mother, who repeatedly claimed "some Spanish blood", Amalia did not welcome it when people she did housework for referred to her -carefully- as "Spanish." She was proud to be Mexican-American.

She did not like the word "Chicano" -which in her youth, in El Paso, Texashad been a term of disapproval among Mexicans ${ }^{21}$

20 Loc. cit.

21 John Rechy, The Miraculous Day of Amalia Gómez, Nueva York, Arcade Publishing Little Brown and Co., 1991, p. 4. "A ella le molestaban sus pestañas caídas -Pero no tanto como a algunas personas de la generación de su madre que las desdeñaban porque eran supuestamente el símbolo del predominio de sangre india. A diferencia de su madre, quien repetidamente clamaba tener "algo de sangre española", Amalia no agradecía que la gente con la cual trabajaba en la casa se refiriera a ella - cuidadosamente- como "española". Ella estaba orgullosa de ser méxico-americana. No le gustaba la palabra "chicano" - la cual en su juventud en El Paso, Texas- había sido un término de desaprobación entre los mexicanos". 
Ambos textos hablan de misticismo y de milagros en la comunidad chicana y vinculan el catolicismo con la solidaridad étnica y la resistencia a la opresión; en particular la novela de Rechy cuestiona de manera amenazante la forma en cómo operan los milagros para reforzar la pasividad y el auto sacrificio de la mujer chicana. ${ }^{22}$ En estas dos novelas los milagros son metáforas para resistir las fuerzas que amenazan la sobrevivencia de los caracteres chicanos.

Los problemas que surgen en la producción y recepción de la literatura chicana, puertorriqueña y cubana en Estados Unidos, en relación a la construcción ideológica de la identidad, es que al penetrar en la imagen del sujeto "otro", ya sea chicano, puertorriqueño o cubano creado por el autoproclamado grupo nacional en aquel país, la literatura de estos grupos étnicos mantiene un estatus marginal y suplementario impuesto; sin embargo, para evitar su extinción dicho "corpus" literario ha formulado una práctica textual que tiende a reformular la identidad sociocultural. Lo anterior constituye una práctica típica de las literaturas étnicas en un intento por recuperar su propia tradición frente a la amenazante mayoría nacional. A pesar de que los grupos latinos de Estados Unidos están ganando terreno para ser reconocidos como parte integrante de la cultura estadounidense, la noción crucial de identidad continúa siendo cuestionada permaneciendo como un problema complejo y difícil de ser estudiado.

A pesar de que para las agencias del gobierno norteamericano es conveniente agrupar a todos los chicanos, los puertorriqueños, los cubanos, los centro y sudamericanos y muchos otros hispanos con un solo término, hispanos o latinos, esto es más una ilusión de carácter monolítico para Estados Unidos, que una realidad.

Los tres grupos analizados son muy diversos y su literatura no puede ser reducida a simples generalizaciones sin desatar violencia. Es mejor tratar de comparar y contrastar las obras para entender cómo las diferencias culturales y de asimilación afectan el proceso de producción literaria.

${ }^{22}$ Ibid., p. 248. 
Pero irónicamente uno puede también encontrar denominadores comunes que unifican, por ejemplo, a los chicanos y puertorriqueños ante los ojos de los extraños, y encontrar también puntos de divergencia: herencia española, raíces históricas latinoamericanas, cruce de razas, estatus de minorías dentro de Estados Unidos como inmigrantes y un lenguaje común. Ambos grupos reconocen antecedentes de la cultura hispana, pero su significante difiere para cada uno.

Esto tiene que ver con sus lazos históricos como latinoamericanos. La cultura mexicana tuvo un periodo en contra de la cultura ibérica (reconocido como antigachupín) después de la Independencia en 1821 y, posteriormente, durante la Revolución de 1910 y debido a ello, la nación mexicana desarrolló una identidad no-española. Por su parte, Puerto Rico permaneció como colonia española hasta finales del siglo XIX y pasó directamente al dominio y a la esfera de influencia de Estados Unidos, por ello no desarrolló jamás la misma identidad independiente como lo hizo México. Se podría decir que Puerto Rico no ha tenido independencia y permanece como una colonia.

Por otra parte, algunos chicanos claman que el suroeste norteamericano es también un territorio colonizado, sin embargo fue independiente cuando menos treinta años. Los inmigrantes mexicanos que han cruzado la frontera desde los años posteriores a 1848, traen con ellos el sentimiento de nacionalidad independiente. ${ }^{23}$

Un punto de divergencia es que los chicanos provienen de culturas de tierra adentro y del México norteño y central, cuando la cultura puertorriqueña y la cubana son caribeñas y de la costa. Si los chicanos hubieran sido influidos por los patrones culturales costeños de Veracruz y Yucatán, podrían ser más parecidos a los puertorriqueños y a los cubanos, pero el hecho es que México mismo no es caribeño en su ser, por ello los chicanos pueden estar culturalmente más cercanos a los colombianos de Bogotá o a los argentinos de Mendoza, que a los nativos

23 Bruce-Novoa, Retrospace. Collected Essays on Chicano Literature, Houston Texas, Arte Publico Press, 1990, p. 28. 
de San Juan. Otro punto de diferencia es que los chicanos han heredado la ideología agraria de la Revolución mexicana, lo que produce en ellos una preocupación intensa sobre la propiedad de las tierras, desde una pequeña granja hasta una casa, o la cuestión de poseer un territorio nacional, lo que los "nuyoricans" no externan a través de su literatura. ${ }^{24}$

Estas diferencias se refuerzan con los patrones migratorios, que han acomodado a los puertorriqueños y cubanos en la costa suroeste y noroeste y a los mexicanos en los estados del suroeste americano. Los tres grupos se concentran en las ciudades y áreas urbanas en general, pero los puertorriqueños son más citadinos que los mexicanos. La literatura chicana está llena de imágenes de campesinos y migrantes de los campos y de las granjas. La literatura "nuyorican" está más involucrada con la descripción de los guetos y el estilo de vida de Nueva York. Además el oeste norteamericano siempre ha significado el sueño de adquisición de tierras, cuando que en el este las ciudades representan a los inquilinos del gueto. Añadido a esto existe la ideología propagada en la literatura chicana de que el suroeste pertenecía a los chicanos porque fue tomada de México a través de una invasión ilegal, y por ello uno puede entender por qué la literatura chicana contiene una vena de propiedad de la que carece la literatura "nuyorican". ${ }^{25}$ Ambos grupos son considerados minorías de bases raciales mezcladas. Sin embargo el elemento predominante no hispano difiere en cada caso. Los chicanos se ven como la mezcla de españoles e indios, pero los puertorriqueños enfatizan su herencia negra y española.

Por ello Miguel Méndez como chicano de Arizona, se siente cercano a los indios nativos americanos, mientras que Alurista usa la mitología precolombina como base para proyectar la identidad chicana. En el lado de los puertorriqueños, Piri Thomas lucha con la idea de ser negro, pero no "un negro", como en Down These Mean Streets (1967) Esta diferencia está compuesta por el hecho de que existe un sentimiento anti-negro en las comunidades chicana y mexicana, así como un resen- 
timiento sobre lo que es percibido como favoritismo hacia el negro en los círculos gubernamentales. Estos sentimientos de envidia y falta de credibilidad están proyectados a la comunidad puertorriqueña cuando ellos enfatizan su negritud. En la literatura, la influencia negra es más obvia en la poesía escrita en inglés, por su ritmo acentuado por la repetición de palabras. Algunos poetas chicanos, como Alurista, han cultivado deliberadamente una voz negra la cual ellos mezclan con su estilo personal, pero estos usos son reconocidos y clasificados como elementos extranjeros. Los escritores chicanos "pintos", que son los presidiarios, muestran más similitudes con el habla de los negros por el predominio de éstos en las prisiones, pero las divisiones étnicas y culturales también se dejan sentir dentro de los muros de las cárceles y la poesía "pinto" reciente muestra más influencia de los escritores chicanos de fuera. ${ }^{26}$

En términos de mestizaje racial, lo que ambos grupos comparten es la identificación con su lado no español. Sin embargo, ni los chicanos, ni los puertorriqueños se consideran completamente como un mismo grupo, a pesar de los intentos gubernamentales anglosajones de unirlos con la etiqueta de "hablantes de español", ya que aun la lengua tiene matices diferentes en cuestiones fonéticas y léxicas. En literatura el uso del español difiere. Uno puede encontrar el uso de español e inglés en el mismo texto entre los escritores chicanos, pero no entre los puertorriqueños. El code-switchig, como los lingüistas han dado por llamar a esta mezcla, lo hicieron legítimo los poetas como José Montoya, Alurista y Ricardo Sánchez en los años sesenta, y fue usado extensivamente, aunque no todos los escritores chicanos o puertorriqueños lo usan para escribir, ya que muchos lo hacen en inglés o en español, y algunos en ediciones bilingües, con traducciones del lenguaje original. ${ }^{27}$

Los escritores puertorriqueños prefieren permanecer en un solo lenguaje, aunque algunos poetas recientes como Víctor Hernández Cruz,

26 Bruce-Novoa, op. cit., p. 29.

27 Ibid., p. 30. 
Pedro Pietri, Tato Laviera y Miguel Algarín, están usando cada vez más el code-switching. Ambos grupos utilizan anglicismos, pero no los mismos, ya que algunas veces una misma palabra tiene diferentes connotaciones para cada grupo, por ello, irónicamente, es este uso del lenguaje que caracteriza el habla de los chicanos y los puertorriqueños dentro de la familia de patrones de habla latinoamericana, la que los distingue.

Podríamos añadir que ambos grupos están preocupados por las injusticias que sufren los hispanos en la esfera de influencia de Estados Unidos. Sin embargo la apreciación de su propio estatus como gente difiere notablemente. Por un lado, la literatura chicana ha producido varios libros con motivos épicos, en un intento por crear una historia y una mitología sobre la visión de los chicanos como nación. Trabajos anteriormente mencionados como el de Rodolfo Corky González I Am Joaquin (1972), el de Sergio Elizondo Perros y antiperros (1971), el de Alurista Flor y canto en Aztlán (1971), o el de Miguel Méndez Los criaderos humanos (1975) han producido una base ideológica para el propósito de cohesión cultural. También han creado arquetipos de sobrevivencia cultural a pesar de las presiones de asimilación, como los "pachucos" y los "campesinos". Escritores como Luis Valdés y José Montoya transformaron la figura del "pachuco" en los precursores de la conciencia chicana contemporánea. Representan también la resistencia militante tanto en la cultura estadounidense como en la mexicana, por lo que simbolizan la síntesis intercultural del chicanismo. Los campesinos y migrantes representan la fuerza de trabajo sobreexplotada, utilizada por la sociedad hegemónica para mantener un alto nivel de vida de la clase media estadounidense, a expensas de los trabajadores mal pagados. También representan la voluntad de los mexicanos de abandonar México para cambiar su manera de vida y obtener algo mejor en Estados Unidos. Sin embargo en la literatura puertorriqueña no existe nada similar ni en temática ni en arquetipos. ${ }^{28}$

${ }^{28}$ Ibid., pp. 30-31. 
Los temas favoritos de ambos grupos son la inmigración y la deculturación. La obra de René Marqués, La carreta: drama en tres actos (1963), puede ser comparable con la de Richard Vázquez, Chicano (1970), e incluso con la de Ernesto Galarza Barrio Boy (1971). Las familias dejan su casa rural en su tierra natal para irse a la ciudad en Estados Unidos, en donde los jóvenes adoptan nuevas costumbres. La unidad de la familia se ve amenazada y la generación de los viejos llora por el pasado y las tradiciones perdidas.

Ambas literaturas exploran el Bildungsroman dentro del ambiente migratorio, sin embargo los chicanos ponen en ello más énfasis. El libro del puertorriqueño Piri Thomas, Down These Mean Streets (1967), relata las luchas de un joven puertorriqueño en contra de su condición de negro y en la prisión; el de Pedro Juan Soto, Hot Land, Cold Season (1970), explora el retorno de un joven puertorriqueño nacido en Estados Unidos a la isla, en donde se ve confrontado con la alienación. Las obras chicanas como la de José Antonio Villarreal, Pocho (1959), la de Rudy Anaya, Bless Me Ultima (1972), la de John Rechi, City of Night (1963), y otras más, exploran los ritos chicanos de pasaje en una gran variedad de escenarios sociales. Lo que las distingue es la inclusión de la escritura misma como un factor esencial de maduración. Muchos trabajos de los chicanos se pueden leer como retratos de los mismos artistas cuando eran jóvenes. De esa manera, la escritura viene a ser un medio para conservar la cultura y al mismo tiempo una vía para definirse en una situación nueva dentro de Estados Unidos. Esta preocupación no se percibe en gran medida en la literatura puertorriqueña. ${ }^{29}$

A pesar de que esta última algunas veces tiende a buscar la unidad con la isla, y a crear una nueva síntesis cultural, no está centrada en la tierra de origen. Militantes independentistas desaprueban esta idea de una identidad separada para los puertorriqueños que residen en el continente, así como lo hace una pequeña minoría de mexicanos entre los 
chicanos. Miguel Algarín (poesía Nuyorican), Judith Ortiz Cofer (Creative Writing o escritura creativa), y Jaime Carrero (The FM Safe), contribuyen al llamado "género de las minorías" porque utilizan el término "nuyorican", que algunas veces tiene un significado peyorativo, con un nuevo orgullo, de la misma manera que los escritores chicanos lo hicieron en los años sesenta, y tal vez éste sea el primer paso para una ideología de la diferencia, ${ }^{30}$ ya que representan la personalidad puertorriqueña mediante la construcción lingüística.

Como dato importante Earl Shorris, crítico del New York Times Book Review, dice que están ocultando la literatura nuyorriqueña y que solamente se encuentra disponible en librerías de "barriada", sin embargo Faythe Turner, autora de Puerto Rican Writers at Home in the USA (1991), señala que esto es mentira, ya que Judith Ortiz Cofer fue nominada para el premio Pulitzer, y es reconocida por The National Endowment for the Arts (Consejo Nacional par las Artes), junto con Ed Vega, y Martín Espada, premiado por el International $P E N,{ }^{31}$ además de otros autores puertorriqueños no considerados “nuyoricans”, como José Ángel Figueroa, Luz María Umpierre, Magdalena Gómez, Rosario Morales y Aurora Levíns Morales, y que esto es ejemplo claro de la aceptación de la literatura latina en el mercado literario convencional. ${ }^{32}$

30 Ibid., p. 32.

31 PEN American Center, founded a year later, works to advance literature, to defend free expression, and to foster international literary fellowship. The Center has a membership of 2,900 distinguished writers, editors, and translators. International PEN, the worldwide association of writers, was founded in 1921 to promote friendship and intellectual cooperation among writers everywhere; to emphasize the role of literature in the development of mutual understanding and world culture; to fight for freedom of expression; and to act as a powerful voice on behalf of writers harassed, imprisoned and sometimes killed for their views.

32 Rafael Ocasio y Judith Ortiz Cofer, "La deconstrucción de la invisibilidad latina o la dialéctica de la representación puertorriqueña", en Alberto Moncada, Carmen Flys Junquera, José A. Gurpegui Palacios [eds.], El poder hispano. Actas del V Congreso de Culturas Hispanas de los Estados Unidos, Madrid, Universidad de Alcalá, España, julio, 1992, pp. 499-518. 
Ya desde 1978 Edna Acosta Belén ${ }^{33}$ marcaba la independencia de los escritores nacidos en el continente de los puertorriqueños insulares, y propuso la inclusión de los "nuyoricans" en el género testimonial de “escritura para minorías". Actualmente, Nicolás Kanellos rechaza el término de "literatura de migración" para referirse a la literatura chicana/ latina, y le llama "literatura norteamericana del campo y de la ciudad, que se basa en tradiciones literarias norteamericanas e hispanoamericanas y reclama sus derechos tanto civiles como estéticos." ${ }^{34} \mathrm{Si}$ comparamos los estilos literarios, aquellos puertorriqueños que residen fuera de Nueva York muestran una estética diferente a los "nuyoricans", tanto así que Margarita Fernández Olmos, especialista en la literatura "nuyorican", los ha catalogado como: escritores que escriben en inglés, poseen carreras universitarias, conocen a fondo la tradición puertorriqueña y latinoamericana y escriben fuera del estilo "nuyorican". 35

Para los emigrantes latinos en general, y sus descendientes de primera o segunda generación ya aculturados de cierta manera a la cultura norteamericana, la mayor confrontación con el sistema reside en la marginalidad de los organismos de decisión y poder político y social, por lo que experimentan la "otredad", es decir la marginación de la colectividad nacional y la "invisibilidad", representados por la ausencia total de caras o voces latinas en los programas televisivos o radiales, con excepción de las cadenas de Univisión, que es especial para la audiencia hispana y dirigida a los consumidores latinos. Acentuado lo anterior por los estereotipos negativos y raciales ${ }^{36}$ que presentan al latino/hispano como

33 Edna Acosta Belén, "The Literature of the Puerto Rican National Minority in the United States", Bilingual Review, núms., 2-3, enero-agosto, 1978, pp.109-110.

34 Nicolás Kanellos, "La literatura hispana de los Estados Unidos y el género autobiográfico", en Rodolfo J. Cortina y Alberto Moncada [eds.], Hispanos en Estados Unidos, Madrid, Ediciones de Cultura Hispánica, 1988, pp. 221-230.

35 Margarite Fernández Olmos, "Exiliados lingüísticos: el dilema del escritor" en Sobre la literatura puertorriqueña de aquí y de allá: aproximaciones feministas, Santo Domingo, Omega, 1989, pp. 75-82.

36 Ibid., p. 501. 
el pendenciero, el supersticioso, el bailador incasable, el latin lover, ficcionalizados al extremo.

De la misma manera estos modelos negativos se extienden a la comunidad puertorriqueña, como por ejemplo Nicolasa Morh autora de Nilda (1973), es considerada por su mismo público intruder u outsider, por su posición de utilizar el inglés para escribir. La literatura puertorriqueña en Estados Unidos ha recibido más atención en la ciudad de Nueva York, ya que ahí se concentra la mayoría de los puertorriqueños inmigrantes, así la megalópolis con sus barrios latinos se ha convertido en el tema unificador para los escritores "nuyoricans", que exploran sus propias experiencias en el proceso de aculturación, alimentada por la estética posmodernista de la cultura popular norteamericana y puertorriqueña. ${ }^{37}$

La invención popular se detiene detalladamente en la descripción positiva de los atributos de su etnia y en cada uno de los tres grupos que describimos, siempre sale a flote la fiereza, el valor y el temple de "la raza" entre los chicanos, de la belleza de Cuba, la añoranza de los parientes que permanecen bajo el régimen castrista y la nostalgia de lo que pudo haber sido la vida en La Habana entre los cubanos. Por otra parte, entre los puertorriqueños encontramos la calidez y hermosura de los paisajes, el colorido deslumbrante y el olor característico de la isla, los ritmos cadenciosos de la música y del caribe, en oposición con lo descolorido y desabrido de los anglos y su cobardía al atacar a gente desvalida como los migrantes y el despojo que han hecho de las tierras de los indios y mexicanos, la discriminación de los morenos y negros. Para todos es el villano traidor, aunque nunca es más de lo que el estigma le confiere, sin embargo es la maldición insalvable de un imperialismo mítico.

La comunidad de antaño para cada escritor chicano/latino es un espacio con límites conocidos y más allá todo es campo. Hoy día en las complejas ciudades nadie puede abarcar todos los itinerarios ni puede pa-

${ }^{37}$ Ocasio, op. cit., p. 500. 
sar revista a la inmensidad de ofertas simbólicas deshilvanadas que se expanden día a día sin límites ni misericordia. ${ }^{38}$ Las ciudades son un mito del liberalismo en donde se pretende sustituir la tradición por la modernización, lo artesanal por la producción en masa, el mito y la superstición por el saber científico y lo rural, natural y callado, por lo urbano colmado de luces artificiales y ruidos diferentes y excesivos, pero aunque el centro ya no está situado en el pasado, éste no se ha ido, y coexistimos con la infinidad de fracasos y contradicciones de la modernización. Esto es lo que García Canclini ${ }^{39}$ denomina "heterogeneidad multi-temporal" cuyo mejor ejemplo son las instituciones políticas, que son la mezcla de tradición autoritaria, caudillismo, movimientos sociales democráticos, paternalismo, neoliberalismo, etcétera. ${ }^{40}$

Lo cierto es que se vive dentro de una heterogeneidad cultural que está rodeada de multitemporalidad que permanecerá por mucho tiempo a juzgar por la velocidad de los cambios que se están produciendo en nuestra época. Buena parte de nuestra modernidad es meramente superficial o pierde su significación y su función de acuerdo a como el usuario utiliza los artefactos producto de la tecnología moderna, como celulares o computadoras para adquirir estatus o poder social.

Lo que hemos denominado posmodernidad es un ciclo tendiente al individualismo, al consumismo, una búsqueda frenética en el cual la piedad, el humanismo o los sueños son imposibles y ni siquiera sabemos si se puedan plantear objetivos grupales. Quizá por ello debemos volver al pasado para encontrar el presente, como dijo Marshall Berman "puede suceder que volver atrás sea una manera de volver adelante". ${ }^{41}$

38 Andrés L Mateo, Al filo de la dominicanidad, Santo Domingo, República Dominicana, Editora de Colores, Librería la Trinitaria, 1996, pp. 25-27.

39 Néstor García Canclini, Culturas híbridas: estrategia para entrar y salir de la modernidad, México, Grijalbo, 1990.

40 Mateo, op. cit., p. 27.

${ }^{41}$ Mateo cita una frase de Marshall Berman: Todo lo que es sólido se diluye en el aire. 
Pero debemos preguntarnos si logramos realmente entender qué es la identidad étnica y de dónde surge. Hemos planteado que la identidad étnica pertenece a aquellas personas que tienen un sentido de pertenencia a un grupo de personas determinado, que se reconocen a sí mismas como gente. Se consideran miembros de ese grupo, tienen un sentido de compartir un pasado histórico y un futuro compartido y ven su vida situada dentro del hilo de su historia. Están unidos a sus tradiciones, símbolos y su historia es una fuente de auto estima. Pero tenemos que preguntarnos si estos grupos de chicanos, méxico-americanos, puertorriqueños, cubanos, dominicanos, ecuatorianos, colombianos, uruguayos, etc., que viven en Estados Unidos, y que los han agrupado con los términos de latinos o hispanos, están desarrollando realmente una identidad étnica común, una "pan-identidad" que descansa en los patrones comunes de cultura latinoamericana, lenguaje español y experiencias de adaptación a la vida norteamericana, o por el contrario, estas diferencias en historia, clase social, ocupación, ciudadanía, son tan profundas, que a pesar de que comparten el español, su cultura y tradiciones latinoamericanas, sus identidades permanecen aisladas como mexicanos, puertorriqueños, cubanos, dominicanos, chilenos, ecuatorianos, etcétera.

En este punto se puso la atención a la variable de la naturaleza de los grupos étnicos y cómo se han ido conformando a lo largo de diferentes dimensiones y transformado a través del tiempo. Al usar la distinción entre comunidades de cultura y comunidades de interés ${ }^{42}$ podríamos argumentar que en el presente los chicanos e hispanos o latinos en Estados Unidos constituyen una comunidad de cultura, pero todavía no una comunidad de interés, a pesar de la participación en los movimientos por la reivindicación de los derechos civiles o en los movimientos sindicales como el organizado por César Chávez.

42 Stephen Cornell, Communities of Culture, Communities of Interest: On the Variable Nature of Ethnic Groups, Unpublished paper, Harvard University, Department of Sociology, 1985. 
En una comunidad de cultura la gente está más cercanamente vinculada por su participación en una misma cultura, en un sistema de significados compartidos, con patrones de interacción, de conducta y costumbres que reflejan una tradición común. Los chicano/latinos en Estados Unidos están inmersos en una comunidad de cultura en virtud de su origen latinoamericano y sus lazos culturales con el lenguaje español y su religión católica. Ellos se reconocen a sí mismos como un reflejo de patrones de interacción social. Cuando están en grupos mezclados frecuentemente se dirigen a ellos mismos como latinos.

En una "comunidad de interés" $" 43$ la gente está unida sobre las bases de compartir una serie de intereses económicos o políticos y se puede afirmar que los chicano/latinos en Estados Unidos en general, no están involucrados en tales comunidades de interés. Sus historias de migración son muy diferentes, han tenido distintos procesos de incorporación a la sociedad norteamericana, y estos procesos han puesto verdaderos obstáculos para que ellos puedan desarrollar un juego de intereses comunes como latinos o hispanoamericanos.

Los estudios sociológicos han reemplazado el concepto de "asimilación"44 que describe un proceso evolutivo natural, donde todo inmigrante o grupo étnico llega eventualmente a tener paridad con la cultura mayoritaria conforme se va asimilando, por el concepto de "incorporación" 45 que no significa un proceso homogéneo y uniforme. Este término acepta que existe una variación considerable en cada grupo para acceder a los recursos sociales, y a las recompensas, tanto por su lu-

43 Silvia Pedraza, Ethnic Identity: Developing a Hispanic-American Identity, en Alberto Moncada, Carmen Flys Junquera, José y A Gurpegui Palacios [eds.], El poder hispano. Actas del V Congreso de Culturas Hispanas de los Estados Unidos, Madrid, Universidad de Alcalá, España, 1992.

44 Milton M. Gordon, Assimilation in American Life, Nueva York, Oxford University Press, 1964.

45 Joe Feagin, Race and Ethnic Relations, Englewood Cliffs, Nueva Jersey, Prentice Hall, 1978. 
gar de origen, como por proceso continuo de acomodamiento en la estructura social de la sociedad receptora.

La "identidad étnica básica" derivada de la pertenencia a un grupo étnico, está compuesta por lo que se llama uniones y afinidades que los individuos adquieren al nacer, ${ }^{46}$ así como la historia y los orígenes del grupo. La cultura pasa a él automáticamente junto con la nacionalidad, filiación tribal si es el caso, lenguaje, religión y sistema de valores, así como la ética y la estética de la cultura, por lo tanto, la identidad del grupo básico es fundamental porque de ella se deriva y está hecha la historia, el arte, la religión el folclore y la literatura. Ser mexicano, chicano, puertorriqueño o cubano, chileno, ecuatoriano, etc., son identidades primordiales, y bajo este esquema, puede ser posible que estos grupos que viven en Estados Unidos puedan desarrollar una identidad chicana o latina, sin perder la primera, sino añadiendo la segunda.

Si por el contrario, las lealtades étnicas reflejan y son mantenidas por el interés socioeconómico fundamental del grupo, la identidad étnica puede ser una elección que la gente haga en un contexto social determinado, y que sobrevive solamente si tiene ciertos usos sociales relevantes. ${ }^{47}$ Por ello consideramos muy importante en este punto, conocer el contexto social para entender qué hace posible y probable una alianza étnica. Sin embargo la insistencia en que la identidad colectiva es solamente producto de intereses colectivos percibidos, pierde de vista el hecho que lo contrario pueda ser verdad, o sea que una identidad colectiva puede delinear la percepción de intereses colectivos y guiar las elecciones económicas y políticas.

Existe otra postura que se basa en la emergencia de una nueva etnicidad, en donde se postula que la identidad es generada y cristaliza

46 Harold Issacs, "Basic Group Identity: The Idols of the Tribe", en Nathan Glazer y Daniel P. Monyham, Ethnicity: Theory and Experience, Boston, Harvard University Press, 1976.

47 Orlando Patterson, "Context and Choice in Ethnic Allegiance: A Theoretical Framework and Caribbean Case Study", en ibid. 
bajo condiciones estructurales que refuerzan el mantenimiento de las redes familiares y de amigos, que se pueden resumir en posiciones sociales, económicas y ocupacionales comunes, estabilidad y concentración residencial, y dependencia de instituciones y servicios comunitarios compartidos. Generalmente los inmigrantes suelen vivir en los mismos barrios, guetos o enclaves étnicos, en determinadas ciudades, en los cuales comparten comida, tiendas, escuelas, iglesias, organizaciones de ayuda mutua, periódicos, etc. Esto refuerza su identidad étnica y su solidaridad y los inmigrantes se convierten en dos comunidades, una de cultura y otra de interés, predicadas o sostenidas en sus experiencias en el gueto urbano o el barrio.

Sin embargo, los grupos de inmigrantes como los mexicanos, ahora llamados chicanos, los puertorriqueños y los cubanos han estado geográficamente dispersos, no comparten condiciones estructurales que puedan servir como bases para construir una identidad común. La inmigración mexicana ha estado concentrada en el suroeste, especialmente en barrios de ciudades de California, Nuevo México y Texas, los cubanos en Miami y los puertorriqueños en el Harlem de Nueva York. Esta dispersión geográfica trae aparejada la clase social de origen, así como los motivos de la migración, el tiempo de inserción dentro de la comunidad angloamericana y las relaciones políticas con el gobierno estadounidense, lo que hace que estas comunidades aún se perciban como diferentes.

Con todo lo expuesto anteriormente podríamos adelantar que el siguiente paso lógico de esta búsqueda cultural podría ser la síntesis de la identidad de los cubanos, "nuyoricans" y los chicanos dentro de una etnicidad hispana o latina. Sin embargo ésta no es una cuestión de planeación racional, ya que si lo fuera, el Melting Pot podría haber funcionado mejor. Los tres grupos comparten situaciones similares y tal vez compartan el paradigma de resistencia a la destrucción caótica creando una diferencia, una identidad alterna, que se verá reflejada en su escritura, es decir, en una ficción colectiva. 